\title{
An Investigation of the Relationship between EQ and Decision-making Style of Investors in Stock Exchange Market (Case Study: Esfahan)
}

\author{
Najmeh Shafiei Varzaneh \\ Department of Humanities Sciences, Isfahan (Khorasgan) Branch, Islamic Azad University, Isfahan, Iran \\ najmeh_shafiei_2012@yahoo.com \\ Saeid Aliahmadi \\ Department of Humanities Sciences, Isfahan (Khorasgan) Branch, Islamic Azad University, Isfahan, Iran \\ saeidaliahmadi@yahoo.com
}

\section{Doi:10.5901/mjss.2015.v6n3p423}

\section{Abstract}

The present study aimed to determine the relationship between $E Q$ (mostly known by its quotient (EQ)) and decision-making styles of stock exchange market investors. The present study is a descriptive survey. Statistical population of the research included all investors in Esfahan stock exchange market using Cochrane formula of unknown population, the sample size is determined to be 96 individuals. In this study, EQ questionnaire of Henry Wezinger (1998) and the questionnaire of Scott and Bruce (1995) were applied to assess the investors' EQ and decision-making style, respectively. Data analysis in two levels of descriptive and inferential statistics using univariate t-test and variance analysis (ANOVA) is conducted by applying spss software. The results show that from the perspective of investors, there is a relationship between rational and intuitive decisionmaking style and emotional intelligence. The results of the research indicated that there is a positive significant relationship between $E Q$ and rational and intuitive decision making. No significant relationship was found between $E Q$ and dependent, impulsive and avoidant decision making. While among the five decision-making styles, rational decision-making style the highest rank and spontaneous decision-making style the lowest rank have had among the styles.

Keywords: Emotional Intelligence (EQ), Decision-making Styles (Rational, Intuitive, Dependent, Impulsive, Avoidant), Esfahan Stock Exchange Market.

\section{Introduction}

EQ represents the ability of an individual to solve daily issues and challenges and helps the individual with prediction for success in life, including professional success and personal life success (Bar - on, 2000). EQ is a recent achievement in psychology which includes recognition and understanding of emotions and feelings of individuals; the recognition and understanding is applied to make proper decisions of daily life. Decision-making style represents the habitual pattern which is used while decision making. In other words, decision-making style of an individual is his/her personality approach to understand and react towards the decision-making task (Thunholm, 2004). Emotion is a precious source of information and helps us make decisions. Decision making occurs frequently in stock exchange market. Decision making is what the investors do in different levels of the organization and move constantly in its space; depending on the situation where they are placed, the investors require certain information or structure to make them able to play their best roles.While decision making, investors deal with several circumstances; in addition, the decisions made are of different natures. Further, changing information available to the investor makes the decision making circumstances different. In cases of sufficient experience and information, decision is certainly made; however, in case of little information and experience, decision must be cautiously made (Sadeqi,2011). Decision making as the main essence of investors' activities is of an important role in all their tasks. Investors choose their decision-making style according to different economical, political and social factors. Investors can get help of the information on their feelings for an efficient decision making. Regarding the new subject of $\mathrm{EQ}$ in investment area, the necessity of finding out a relationship between the concept and decision-making style of investors, with no research history in Iran, is the main aim of the present study. 


\section{Theoretical Framework and Literature Review}

Intelligence has several definitions; one of the closest ones considers intelligence as "a series of cognitive capabilities which allows knowledge acquisition, learning and problem solution". Excitement is a self-conscious emotion in which some concepts such as happiness, sorrow, fear, hatred and love are experienced. Excitement is different from cognitive and voluntary modes; in other words, excitement is related to pleasant and unpleasant aspects of mental process(Aqayar, Sharifie Daramadi,2006).

Emotional Intelligence means having some skills to know who you are and what your thoughts, feelings and consistent behaviors is. In another definition, EQ means recognition of your and other's emotions for behaviors based on ethics and social conscience. Goleman define EQ as the abilities of an individual to maintain the motivation and resist against problems, control themselves in critical circumstances and impulsivity, postpone prosperity, empathize and be hopefu(Aqayar,Sharifie Daramadi, 2008).

According to Goleman, the components of EQ are as follows:

1. Self-awareness: recognition of the emotions you feel and know the reason.

2. Self-management (autronomy): emotional balance is called self-management and is a fundamental capability which plays an important role to control emotional behaviors.

3. Motivation: it means to be productive, effective and creative. Motivation is the ability to energize the others and guide their behavior in spite of weak morale. Motivation applies emotions as a means to achieve the goals.

4. Social awareness (empathy): it is the ability to empathize with the feelings of others and recognizing their viewpoint. Empathy means looking at the world from the viewpoint of the others and entrance to their emotional privacy; it requires understanding, recognition and respond to the others' emotions.

5. Relationship management (communication or social skills): it is the ability to recognize and empathize, effective communication, profound listening and collaboration; this aspect is a complex of the four abovementioned aspects, which helps the individual communicate positively and constantly(Aqayar,Sharifie Daramadi, 2007).

EQ predicts the success of individuals and the way they effectively deal with stresses. Growth and development of emotional intelligent is of major importance. The followings can be mentioned as the importance of EQ:

- Development of responsibility

- Development of happy and lively life

- Dealing with dangerous situation

- Development of cooperative and helpful spirit

Decision making is defined as selection of a way among several others; this definition respects merely one aspect of decision-making process. As the definition implies, the main task of decision maker is receiving possible ways and their subsequent results and then, making the best choice among them(Golman, 2003).

Investors constantly face conditions which demand the necessity of decision making. It indicates the influence and major role of decision making in all tasks of investors and organizational processes. Decisions are our response to environmental events and phenomena; and they include three aspects:

1. There must be more than one solution to respond to the phenomenon. In other words, if there is just one solution to a problem or taking advantage of an opportunity, decision making will be pointless.

2. Decision makers make their predictions of future events on the basis of some probabilities and with a certain reliability degree.

3. Implications of each solution must be assessed in the frame of personal values and goals realization (Alvani, 2008).

Decision making as the main essence of investors' activities is of an important role in all their tasks. Investors choose their decision-making style according to different economical, political and social factors(Rezaeian, 2007).

Decision making is the fundamental and essential component of investment. Investors take their actions by relying on financial information. Therefore, understanding the relationship between decision-making process and EQ plays an important role. The role of EQ in decision-making process is to provide information for the investors to make decision. All the investors need the information related to their decisions. Subsequently, in addition to influential environmental and organizational factors on decision-making style of investors, various personality traits also cause the investors to behave differently towards decision-making opportunities; thus, their decision-making styles are different. Various decisionmaking styles include rational, intuitive, dependent, impulsive, avoidant (Singh, Jeffry, 2004). 
Rational decision-making style: this style indicates the tendency of the decision maker to identify all possible solutions, evaluate the results of every solution through different aspects and eventually select the optimum desirable solution when they face decision-making circumstances(Rezaeian, 2007).

Intuitive decision-making style: it is an autonomous process which is obtained in light of deduced experiences(Robbins, 2002).Those with this style of decision making do not completely decline rational analysis, but intuition plays an important role to make an appropriate decision in particular circumstances including facing a crisis, uncertainty and facing huge unprocessed information and also when, due to complicated nature of the problem and critical condition, data collection on the subject and precise and systematic investigation of the data is impossible.

Dependent decision-making style: this style indicates lack of intellectual and practical independency and also reliance on supports and guidance of the others while decision making (Parker, 2007). Investors with this decisionmaking style need someone by their side to act on their ideas, when they face a problem or opportunity. Rather than consulting and making the final decision on their own, these types of people totally rely and depend on the viewpoints of the others.

Impulsive decision-making style: it indicates the sense of urgency and the tendency of decision makers to make the final decision as fast as possible. In other words, the investors with this style immediately make their decision when they face a decision-making circumstance.

Avoidant decision-making style: those with this style postpone their decision-making task as late as possible and avoid any kind of reaction to the problem. Therefore, avoidant decision-making style can be defined as the effort and tendency to avoid any decision making task and stay away from decision-making opportunities.

\subsection{Role of EQ in Decision-making Process of Investors}

The studies indicated that the distinction between the characteristics of outstanding investors and ordinary ones depends on their EQ. Emotions are a precious source of information and help us make decisions. The studies indicated that when emotion is not connected to the brain, an individual is not able to make decisions, as they do not know how they may feel about their decision. Everyday investors have to make some decisions with successful or unsuccessful consequences. Wrong decisions or being incapable of decision making might turn to chaos and result in credibility decline and depreciation of capital. The outcomes of such process inhibit the investors to achieve the goals and meet the expectations (Aqayar, Sharifie Daramadi, 2007).

Investors' decision making is a major component of their behavior; although their decision-making style and the quality of their final decision is to a great extent influenced by their perception. Investors can get help of the information on their feelings for an efficient decision making. To make more unplanned decisions, an individual needs more judgments and the judgments are based on some non-specific ways through experience, insight and perception. In fact, investors are able to make a reasonable decision only when they take advantage of the information and control their emotion; and this is what we call EQ which determines how they can control their behavior and come up with social problems and make the decisions with positive outcome(Sadeqi, 2011).

\subsection{Literature Review}

Little research has been conducted on this subject, i.e. the relationship between EQ and decision-making styles; however, an enormous body of research is dedicated to similar subjects so that recently, EQ is the subject of many domestic and overseas studies. Nevertheless, more research is required on this subject. Here, some research on this subject or similar studies will be discussed.

Naghizadeh et al. (2010) conducted a research entitled the relationship between EQ and occupational stress of managers and staff of educational hospitals of the University of Medical Science and health services in Tabriz and concluded that having the components of EQ results in the reduction of occupational stress.

Investigation decision-making styles and five factors of personal traits based on the interest styles among 567 students of different faculties in Selkuk University, Deniz (2006) found out that interest styles of students significantly predicts self-determination, decision-making styles and personality traits.

Ebsorn (2010) investigated the relationship between goal orientation, public confidence and decision-making style of managers among 210 Americans who attended a job interview to get a management position in Toluse Market Company. The findings indicated that there was a significant negative relationship between the goal orientation scores of managers and avoidant decision-making style scores. There was no significant relationship between the public trust score and goal orientation score of managers. In addition, the results indicated that goal orientation score can be a distinction index of managers with rational decision-making style and managers with other decision-making styles 
(intuitive, dependent, avoidant). Furthermore, this study provided more documents on inappropriateness of avoidant style for effective decision making. Managers who avoid decision making or postpone it, expose their organization to risk.

To study the effect of control locus on decision-making style of middle-level managers, Thompson (2010) investigated 237 middle-level managers of different industries in the U.S.A.

He found out that there was no relationship between control locus and decision-making styles.

However, both age and gender have statistically significant relationship with the structure of decision-making style and control locus.

\section{Population and Sample}

All investors in stock exchange market in June, 2014. Regarding the population size, the sample size was evaluated by Cochrane formula for unknown population to be 96 individuals. Simple random sampling was used to choose the sample members and 130 investors were selected and were handed the questionnaire in person. 105 investors responded the questions among all.

Equation 1: Cochran formula for the unknown $n=\frac{z^{2} p q}{d^{2}}$

$\mathrm{n}=$ sample size

$\mathrm{z}=$ percent confidence acceptable standard error

$p=$ proportion of the population with a certain attribute

$q=$ proportion of the population lacks certain features

$d=$ degree of certainty

In this study for measuring investors' emotional intelligence from Henry Weisinger (1998) emotional intelligence questionnaire and for measuring the decision-making styles from Scott \&Bruce (1995) questionnaire, and to respond to each of the questions as well as Likert spectrum have been used.

\subsection{Research Hypotheses}

Regarding the new subject of EQ in investment area, the necessity of finding out a relationship between the concept and decision-making style of investors, with no research history in Iran, is the main aim of the present study. On this basis, the research hypotheses are as follows:

1. There is a relationship between $E Q$ and rational decision-making style.

2. There is a relationship between $E Q$ and intuitive decision-making style.

3. There is a relationship between EQ and dependent decision-making style.

4. There is a relationship between $\mathrm{EQ}$ and impulsive decision-making style.

5. There is a relationship between EQ and avoidant decision-making style.

Data were analyzed by the statistical software, SPSS19, on two descriptive and inferential statistics level. Statistical factors including percentage, frequency, mean and standard deviation were applied for descriptive statistics; and univariant t-test, independent t-test and multivariant analysis of variance are used for inferential statistics.

\subsection{Research Findings}

The total 105 subjects consisted of 77 males and 28 females. The mean age of the subjects was lower than 30 and had invested in stock exchange market for less than 2 years. Moat investors of statistical sample (52 subjects) were educated in bachelor degrees and their education fields were non-financial (70 subjects).

Table 1. Mean and Standard Deviation of EQ and Decision-making Styles

\begin{tabular}{ccc}
\hline standard deviation & mean & statistical indices \\
& & Sub scale \\
\hline $0 / 42693$ & $3 / 4946$ & EQ \\
$0 / 48900$ & $3 / 6857$ & RATIONAL DMS \\
$0 / 56144$ & $3 / 6305$ & Intuitive DmS \\
$0 / 70434$ & $2 / 9924$ & Dependent DmS \\
$0 / 73154$ & $2 / 5752$ & Impulsive DmS \\
$0 / 72135$ & $2 / 5943$ & Avoidant DmS \\
\hline
\end{tabular}

Source: the results of the study 
As Table 1 suggests, the mean EQ of 105 selected respondents was 3.4946. The mean of rational decision-making style was calculated to be 3.6857 which was the highest, and the lowest was obtained to be 2.5752 for impulsive decisionmaking style.

\section{Results of the Study}

Table 2. Pearson correlation coefficient calculation for research hypothese

\begin{tabular}{|cccc|}
\hline & Pearson correlation test & \multirow{2}{*}{ Results of Research Hypotheses } \\
\hline significance level & correlation coefficient & sample size & first hypothesis \\
\hline $0 / 000$ & $0 / 459$ & 105 & second hypothesis \\
$0 / 000$ & $0 / 433$ & 105 & third hypothesis \\
$0 / 724$ & $0 / 035$ & 105 & fourth hypothesis \\
$0 / 281$ & $0 / 106$ & 105 & fifth hypothesis \\
$0 / 904$ & $-0 / 012$ & 105 & \\
\hline
\end{tabular}

Source: the results of the study

On the first hypothesis, regarding the above-mentioned table, as the significance value of the test $(0.000)$ is lower than acceptable level of significance, it can be concluded that there is a significant relationship between emotional intelligence and rational decision-making style of investors in stock exchange market. Since the correlation coefficient of the test is positive (0.459), there is a direct relationship between EQ and rational decision-making style.

Regarding the results of investigating the relationship between $\mathrm{EQ}$ and intuitive decision-making style of the investors on Table 2, as the significance value of the test $(0.000)$ is lower than acceptable level of significance $(0.05)$, there is a significant relationship between $\mathrm{EQ}$ and decision-making style of the investors in stock exchange market. Since the correlation coefficient of the test is positive $(0.433)$, there is a direct relationship between EQ and intuitive decisionmaking style.

Regarding larger value of significance value of the third hypothesis test (0.724) than acceptable level of significance (0.05), it can be concluded that there is no significant relationship between EQ and dependent decisionmaking style of the subjects.

The results of correlation test between $\mathrm{EQ}$ and impulsive decision-making style of investors in the statistical sample indicate that the test level of significance (0.281) is larger than acceptable level of significance (0.05); thus, there is no significant relationship between EQ and impulsive decision-making style of the subjects.

According to the results of the fifth hypothesis investigation, since test value of significance $(0.904)$ is larger than acceptable level of significance (0.05), there is no significant relationship between EQ and avoidant decision-making style of the investors in stock exchange market.

\section{Conclusion}

According to the results obtained by investigating the research hypotheses, the first finding indicates a direct relationship between EQ and rational decision-making style of investors in stock exchange market. High EQ means having high levels of self-awareness and self-motivation; and other main factors of EQ allows investors and decision-makers to take advantage of their high EQ and cognition to make the best decision in the situation, instead of following rational style which might not be the best choice and might not provide the best solution in changing conditions and emergency situation. However, the investors with lower EQ are less able to get to know their own and the others' internal feelings and emotions and in many cases, they fail to control their emotion and establishment of an effective social relationship; thus, such investors, completely relying on rational, tend to behave based on rational principles in all decision-making circumstances; and investigating all dimensions and available solutions, they might choose the best choice.

The second finding of the research indicates a positive relationship between emotional intelligence and intuitive decision-making style. However, it must be noted that the investors with intuitive style do not totally reject wise analysis, but they believe that in many circumstances (such as complicated and dynamic environments), it is not possible to follow rational pattern and the solutions must be selected which recognize and confirm their intuition, it is even possible that there is no rational reason for justness of a selected solution. The ability to understand your own and the others' emotion causes the decision makers to balance internal feelings and emotions through their recognition and apply them to 
facilitate decision-making process; and recognizing internal emotion of the staff and those who are influenced by the consequences of the decisions made and the ability to establish effective social relations to facilitate the process of putting the decision into action, they eventually choose the suitable solution.

Another finding of the research indicates an indirect relationship between EQ and avoidant decision-making style of the investors. Those with lower EQ, due to lack of ability to understand their own and others' internal emotion, weakness to control emotions and establish effective social relationship and recognize the unknown circumstances of decision-making, are imposed by stress and high pressure while decision making. An increase in stress may cause the individual to avoid any stressful situation by escaping the decision-making situation and a delay in any type of decision making as long as possible, and it may result in coming into conclusion that the best choice is to ignore the problems and avoid decision making.

Therefore, if we admit that high self-confidence and inner peace are major features of organizational decision makers, so that investors with higher levels of $E Q$ are more capable of reacting to organizational threats and opportunities without escaping decision-making situations and without any passive approach.

\section{Practical Suggestion}

- As the present study indicated a positive significant relationship between EQ of the investors and rational and intuitive decision-making style, it is recommended to investors to make more effective decisions by increasing their EQ skills.

- Decision making is one of the concerns of most investors and the investors appear more successful that are able to make correct and logical decisions; and since the investors with higher EQ make more effective decisions, it is possible to promote the decision-making power of investors through EQ skills training.

- It is recommended that investors make decisions most on basis of logic and reason not on feelings and instant emotion.

\section{References}

Alvani, M. (2008). General management, volume 33, Ney publication, Tehran, 310 pages.

Aqayar, S., Sharifie Daramadi, P. (2006).emotional intelligence and scientific investigations, Sokhan Publications, Tehran, 190 pages.

Aqayar, S., Sharifie Daramadi, P. (2007). Organizational emotional intelligence, Sepahan publication, Isfahan, 303 pages.

Aqayar, S., Sharifie Daramadi, P. (2008). The application of intelligence in the scope of emotion, Sepahan publication, Isfahan, 204 pages.

Bar - on, Reuven. 2000. Emotional and Social Intelligence, Insight From the Emotional Quotient Inventory, the handbook of Emotional Intelligence, theory. development, assessment and application at home, school and in the workplace, Sanfrancisco, pp 365-366.

Deniz, M.G. 2006. The relationships among coping with stress, life satisfaction. Decision- making style \& decision self steem: an investementigation with Turkish university students. Social Behavior and Personality. pp 1161-1170.

Golman, D. (2003). Emotional intelligence and the ability to show kindness and feel kindness. Translated by N.Parsa, Roushd publication, Tehran, 424 pages.

Naqizadeh , H., Tavakoli, M., Miri, M., Akbarzadeh, H. (2009). Investigating the relationship between emotional intelligence and job's stress among the managers and employees of the educational hospitals of Tabriz, psychology journal, volume 16, pages 57-64.

Obsorn, D,G. 2010. The relationship of goal-directioness, generalizd trust, and the managers decision making style disserration of phd. Capella university.345P.

Parker, Andrew M. 2007. Wandi Burine de Bruine \& Baruch Fichhoff. Maximizers versus Satisficers: Decision-Making Styles, Competence and Outcomes, Judgment and Decision Making, vol. 2, no. 6, December 2007, pp 342-344.

Rezaeian, A. (2007). On the management of organizational behavior (concepts, practices, and theories), Elm va Adab (science and politeness) publication, Tehran, 318 pages.

Robbins.s p. 2002. Organizational behavior. Muhammad Ali's translation Parsayyan and Arabs. Tehran: Cultural Research Bureau. $589 \mathrm{P}$.

Sadeqi, A. (2011). On the investigation of the relationship between rmotional intelligence and managers' decision-making styles (a case study of the managers of Polyacril factory). M.A. thesis. Faculty of humanities, Isfahan (khorasgan) branch, Islamic Azad University.

Singh, Romila \& Greenhous, Jeffry H. 2004. The Relation Between Career Decision-Making Strategies and Person-Job Fit: A Study of Job Changers, Journal of Vocational Behavior (64), p202, Available online at www.sciencedirect.com.

Thompson, T. S. 2010. The impact of locus of control on decision making styles of mid-level managers: Capella University. 370P.

Thunholm, Peter. 2004. Decision-Making Style: habit, style or both? Journal of Personality and Individual: Differences, pp 932-933. 